\title{
SYNTHESIS AND CHARACTERIZATION OF THERMOCHEMICAL STORAGE MATERIAL COMBINING POROUS ZEOLITE AND INORGANIC SALTS
}

\author{
Shere L., Trivedi S., Roberts S., Sciacovelli A.*, Ding Y. \\ Birmingham Centre for Energy Storage, School of Chemical Engineering, University of Birmingham \\ Birmingham, B15 2TT \\ United Kingdom \\ *Corresponding Author, E-mail: a.sciacovelli@bham.ac.uk
}

\begin{abstract}
Thermal energy storage (TES) has the potential to decarbonize the heating sector facilitating the penetration of renewable energy sources, in particular solar thermal energy. In this paper we present a study on thermochemical storage material (TCM) composed of inorganic salts hosted in the porous matrix of zeolite $13 \mathrm{X}$ with the addition of carbon material. A series of composites containing different amounts of inorganic salts - $\mathrm{MgCl}_{2}, \mathrm{MgSO}_{4}$ - graphite and carbon nanotubes were prepared by impregnation method. Energy storage and adsorption/desorption rates were assessed using simultaneous thermal analysis (STA) by coupling thermogravimetric (TG) and differential scanning calorimetry (DSC). Microstructure and composition were assessed through scanning electron microscopy and energy-dispersive X-ray spectroscopy. With our composite material we achieved exceptional energy density of $400 \mathrm{~kJ} / \mathrm{kg}$ within the temperature range $30-150^{\circ} \mathrm{C}$. Such features make the material an interesting option for thermal storage in buildings. We attribute the behaviour of the material to to the combination of large zeolite specific area coupled with the heat of sorption of $\mathrm{MgCl}_{2}$, $\mathrm{MgSO}_{4}$.
\end{abstract}

\section{INTRODUCTION}

The energy systems in both UK and overseas are facing unprecedented challenges: The UK government has committed to reduce $\mathrm{CO}_{2}$ emissions by $35 \%$ by 2020 and up to $80 \%$ within 2050 [1]. In order to meet such targets it is imperative to decarbonize the heating sector: about $50 \%$ of UK energy consumption is associated with heat, which is for space and water heating. $80 \%$ of this heat is still supplied by fossil fuels, contributing to $30 \%$ of annual $\mathrm{CO}_{2}$ emissions. Thus it is necessary to overcome the current status quo and move toward a sustainable energy scenario. Different analyses [2] show that a large penetration of renewable energy sources is expected in the near future posing major challenges both on the demand side and on the supply side. In particular, the intrinsic variability of renewables, such as solar thermal energy, must be mitigated using a key technology: thermal energy storage (TES). In fact, TES enables to capture "wrong time" energy and make it available when needed, it helps to shift and shave load peaks, and it improves reliability of energy systems. [3,4].
Thermal energy storage can be classified in three main groups: sensible, latent and thermo-chemical heat storage [5]. Sensible and latent TES have been widely investigated over the last two decades and multiple devices have been commercialized. On the other hand, thermochemical heat storage (TCS) - which has great potential compared to the other two options - needs major research efforts to unlock it massive potential and to bring it closer to application. The operating principle of TCS is based on reversible chemical reactions, which are exploited to store heat. Various candidate reactions have been suggested [6,7] depending on the target application. In this work we focus on TCS application for building applications which limits the operating temperature to $\sim 150^{\circ} \mathrm{C}$ ( $\max$ temperature for air solar collector). Furthermore, we focus on reversible sorption of water onto storage material because of non-toxicity and inexpensive nature. Fig 1 presents the concept of TCS: when solar thermal energy is available it is stored in the TCS device by activating desorption reaction; conversely, thermal energy is retrieved by triggering adsorption reaction when solar input is missing.

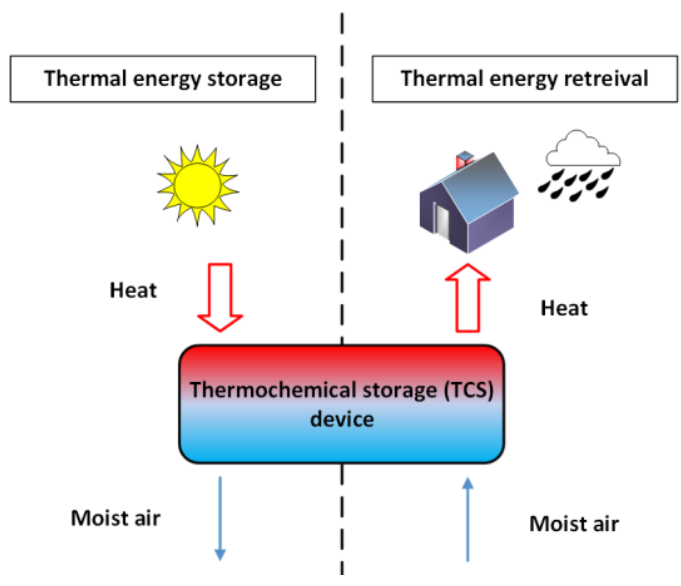

Figure 1 Concept of thermochemical storage.

To implement the TCS concept presented in Fig. 1 it is necessary to develop suitable TCS materials that ensure high energy storage density (i.e. thermal energy stored per unit of mass of material) but also good heat and mass transfer. In this paper we present the performance of a novel TCS material 
composite constituted of a matrix host (zeolite 13X) and hosted inorganic salts (magnesium sulphate $\mathrm{MgSO} 4$; magnesium $\mathrm{MgCl} 2$ ). The zeolite acts a supporting structure enabling better mass transfer toward salts sites where reversible reaction (adsorption/hydration) can occur; the concept is presented in Fig. 2. We synthetized multiple materials and characterized them with multiple techniques including thermogravimetric analysis (TG), differential scanning calorimetry (DSC) and laser flash analysis (LFA). The investigation shows the potential and drawbacks of the proposed thermochemical storage material.

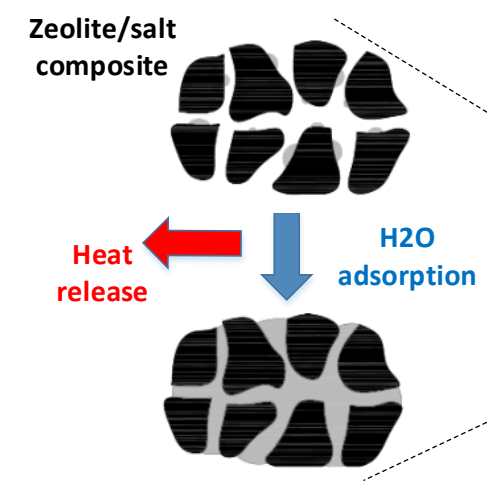

Figure 2 Concept of thermochemical storage.

\section{MATERIAL SYNTHESIS AND METHODS}

All the materials used in the research were supplied by Sigma Aldritch UK. The zeolite $13 \mathrm{X}\left(\mathrm{Na}_{2} \mathrm{O} \times \mathrm{Al}_{2} \mathrm{O}_{3} \times \mathrm{mSiO}_{2} \times\right.$ $\mathrm{nH}_{2} \mathrm{O}$ ) was supplied in the powder from with an average particle size of $2 \mu \mathrm{m}$; magnesium sulphate $\left(\mathrm{MgSO}_{4}\right)$ and magnesium chloride $\left(\mathrm{MgCl}_{2}\right)$ with purity $>99.5 \%$ were employed. At $150^{\circ} \mathrm{C}$ the salts can undergo the following reactions:

$$
\begin{aligned}
& \mathrm{MgSO}_{4} \cdot 6 \mathrm{H}_{2} \mathrm{O} \rightarrow \mathrm{MgSO}_{4} \cdot 6 \mathrm{H}_{2} \mathrm{O}+5.5 \mathrm{H}_{2} \mathrm{O} \\
& \mathrm{MgCl}_{2} \cdot 6 \mathrm{H}_{2} \mathrm{O} \rightarrow \mathrm{MgCl}_{2} \cdot 2 \mathrm{H}_{2} \mathrm{O}+4 \mathrm{H}_{2} \mathrm{O}
\end{aligned}
$$

if water mass transfer is ensured to avoid reaction kinetic limitation. For this reason the impregnation of the salt within a material - the zeolite $13 \mathrm{X}$ - with high specific surface area can provide accessible reaction sites and ensure good mass transfer [8]. Incipient wetting method [9] was used to prepare the composite materials; this involves the impregnation of the host zeolite with an aqueous solution of $\mathrm{MgSO}_{4}$ and $\mathrm{MgCl}_{2}$; the concentration of the solution was determined in order to achieve the desired $\mathrm{MgSO}_{4} / \mathrm{MgCl}_{2}$ ratio in the final composite. The solution was slowly added to the dry zeolite under constant stirring to ensure immediate impregnation. The composite was then dried for $10 \mathrm{~h}$ at $130^{\circ} \mathrm{C}$ in an oven. Finally the composite was hydrate in a custom made humidity chamber for $24 \mathrm{~h}$ under $95 \%$ relative humidity. Table 1 summarizes the compositions of the materials prepared for this study.
Table 1: Materials compositions

\begin{tabular}{llll}
\hline & $\mathbf{M g C l}_{\mathbf{2}} \mathbf{w t} \%$ & $\mathbf{M g S O}_{\mathbf{4}} \mathbf{w t} \%$ & Zeolite wt\% \\
\hline Material A & 15 & - & 85 \\
Material B & 11.25 & 3.75 & 85 \\
Material C & 7.5 & 7.5 & 85 \\
Zeolite 13X & - & - & 100 \\
\hline
\end{tabular}

Multiple methods were used to characterize the composites listed in Table 1. The materials were imaged using a Hitachi TM3030 scanning electron microscope (SEM) equipped with energy dispersive X-ray spectroscopy (EDX) option for elemental analysis. Thermogravimetry coupled with differential scanning calorimetry (TG-DSC) was performed using Netzsch STA 449 F3 Jupiter to quantity the energy storage density and mass change. $10 \mathrm{mg}$ samples were tested in aluminium pans within temperature range $30<\mathrm{T}<150{ }^{\circ} \mathrm{C}$ at a rate of $3^{\circ} \mathrm{C} / \mathrm{min}$ with samples held at constant $30^{\circ} \mathrm{C} / 150^{\circ} \mathrm{C}$ for 15 minutes. All the tests were performed under a $\mathrm{N}_{2}$ flow of $20 \mathrm{ml} / \mathrm{min}$. Thermal conductivity was measured using Netzsch LFA 427; each test was conducted with a laser intensity of $480 \mathrm{~V}$ and laser pulse of $80 \mathrm{~ms}$; Cowan method was user to obtain thermal diffusivity from LFA output signal.

\section{RESULTS}

Fig 3 show the SEM images of the supplied zeolite 13X and the Material A after hydration. The uniform crystalline particles of zeolite can be seen in both the images.
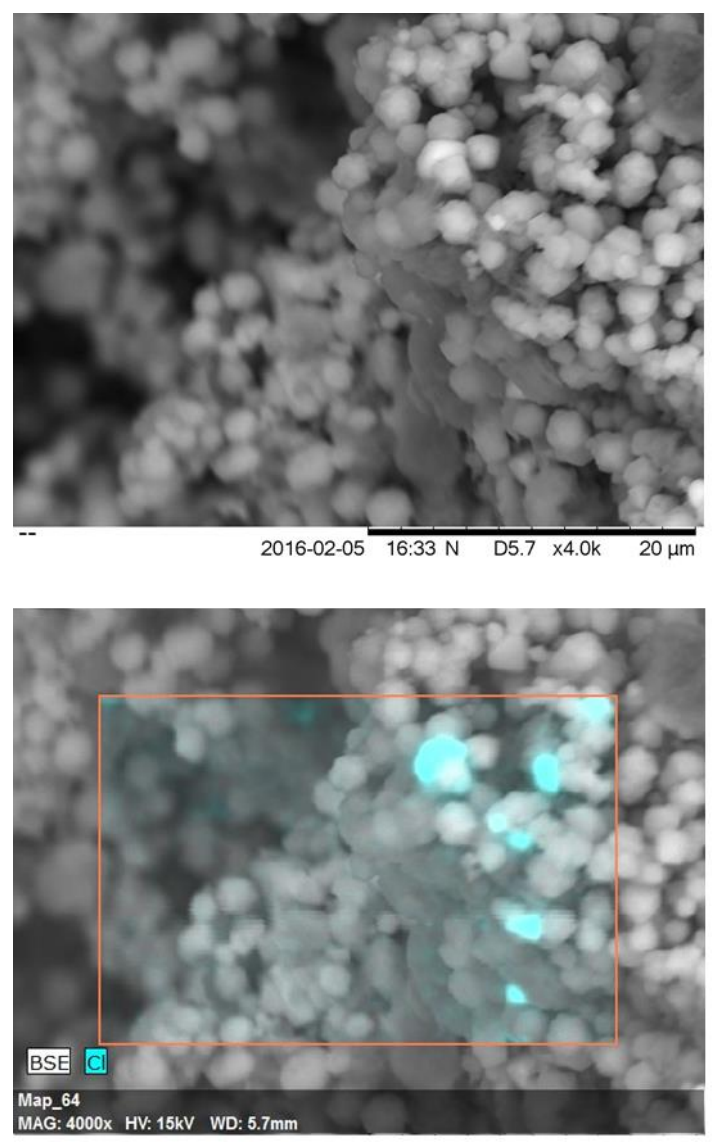

Figure 3 SEM (top) and EDX (bottom) of Material A. 
Using EDX analysis some of the particles in the SEM image prove to contain chloride (shown by blue colour) which confirm the presence of magnesium chloride after the impregnation process. The smaller particle appear to be a crystal of magnesium chloride, while large zeolite particles look coated in the salt. There are no other traces of the salt in the rest of the sample, suggesting most of the salt has been absorbed in to the pores.

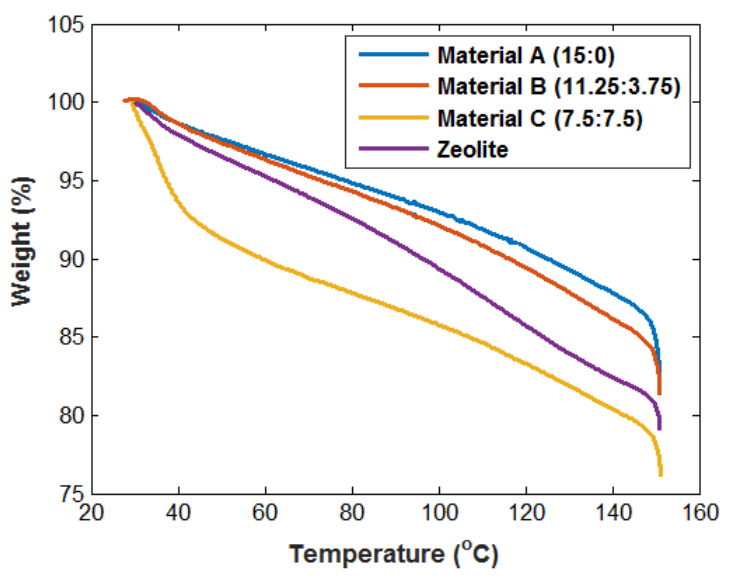

Figure 4 Thermogravimetric plots for the materials in Table 1.

Thermogravimetry and differential scanning calorimetry (TG-DSC) was performed to quantify the mass loss - due to salt dehydration and zeolite desorption - and to evaluate the corresponding heat of reaction, i.e. the energy storage density of the composites. Figure 4 presents the percentage mass loss for the three composites and zeolite $13 \mathrm{x}$ within the range 35 $150^{\circ} \mathrm{C}$ at $3^{\circ} \mathrm{C} / \mathrm{min}$. The zeolite shows a constant mass loss rate indicating that water desorption process is uniform over the considered temperature range. Interestingly, also Material A and Material B show constant mass loss rate but smaller than the one for the zeolite, which indicates blockage and deformation of material pores due to excess of salt impregnation. On the other hand, Material $\mathrm{C}$ present a clear step around $40^{\circ} \mathrm{C}$ which can be attributed to $\mathrm{MgSO}_{4} / \mathrm{MgCl}_{2}$ first dehydration step [10]. Furthermore, it appears that the 50/50\% ratio of salts prevents the pore blockage and facilitate the transport of water molecules from/to reaction sites.

The differential scanning calorimetry results (Figure 5) confirms the outcome of TG: Material C presents the deepest endothermic peak around $40^{\circ} \mathrm{C}$ corresponding to zeolite-salt dehydration leading to better thermal storage performance. Repeated DSC tests consistently show very weak first dehydration step for Material $\mathrm{A}$ and $\mathrm{B}$ which might indicate interactions between $\mathrm{MgSO}_{4}$ and $\mathrm{MgCl}_{2}$. The middle region of composite DSC curves $\left(60^{\circ} \mathrm{C}<\mathrm{T}<120^{\circ} \mathrm{C}\right)$ shows similar behaviour but with smaller heat of desorption compared with pure zeolite $13 \mathrm{X}$, probably due to pores partially blocked by salts. Finally, at $\mathrm{T}>140^{\circ} \mathrm{C}$ next dehydration causes further weight loss (Fig. 4) and heat of dehydration (Fig. 5). However, the target application - storage of solar thermal energy in buildings - limits the maximum temperature to $150^{\circ} \mathrm{C}$, thus the dehydration step above $140^{\circ} \mathrm{C}$ cannot be fully exploited.

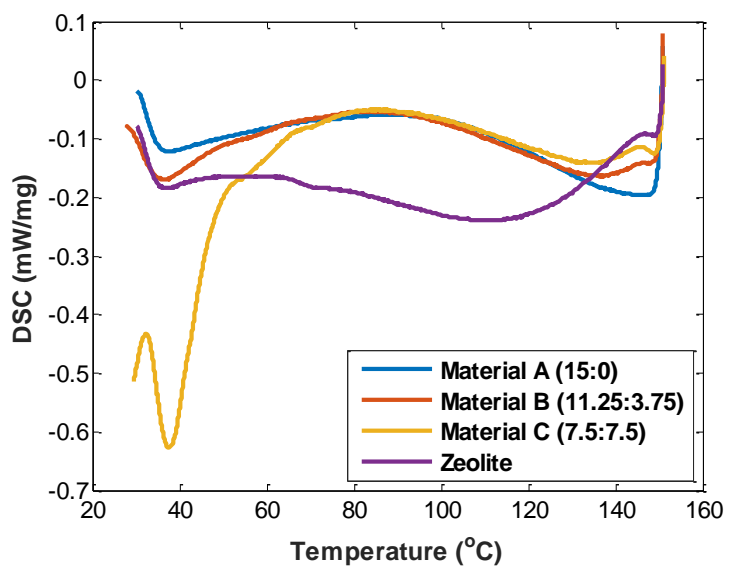

Figure 5 Differential scanning calorimetry plots for the materials in Table 1.

The bar chart presented in Fig 6 summarizes the energy storage density for the three composites and the zeolite 13X. As expected from the TG-DSC analysis Material C achieves the highest energy storage density due to combination of hydration reaction and better access to reaction sites. The blockage of pores - which reduced water mass transfer - is critical. Limited access to pores due to salt presence can detriments the performance access to reaction sites can leads to composites with energy storage density smaller than the pure zeolite.

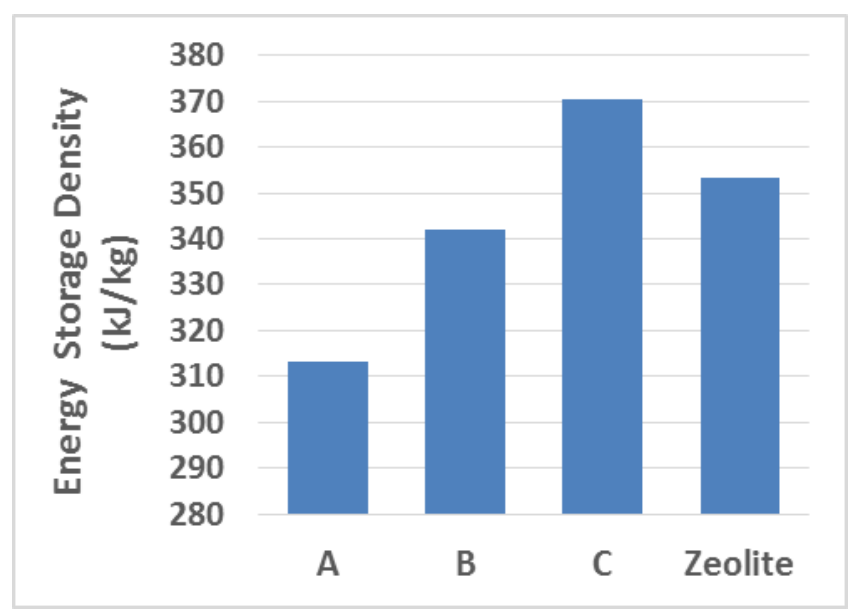

Figure 6 Comparison of energy storage density for formulated materials.

Beside mass transfer, heat transfer plays a major role in the performance of thermochemical storage device. The heat stored in the system should be easily recovered by means of an efficient heat transfer process between the working fluid (moist air in this case) and the thermochemical storage material. Thermal conductivity of dramatically affects heat transfer within TCS materials and intraparticle heat diffusion. Thermal conductivity of Material A was measured at $\mathrm{T}=30 / 80 / 150^{\circ} \mathrm{C}$ by 
laser flash analysis using three laser shots for each temperature; the corresponding results are presented in Fig. 7. Thermal conductivity is in the order of magnitude of other thermal storage materials [5] and can significantly heat transfer rates. To mitigate this drawback the thermal properties of the material can be enhanced with highly conductive elements. In the present work multiwall carbon nanotubes (1\% in weight) were added to Material A to increase thermal conductivity. Figure 7 shows that at room temperature a remarkable 35\% increase in thermal conductivity is achieved. Such an improvement is particularly beneficial since at nearly room temperature the material should be able to supply heat at a good rate to satisfy the user request (i.e. the building).

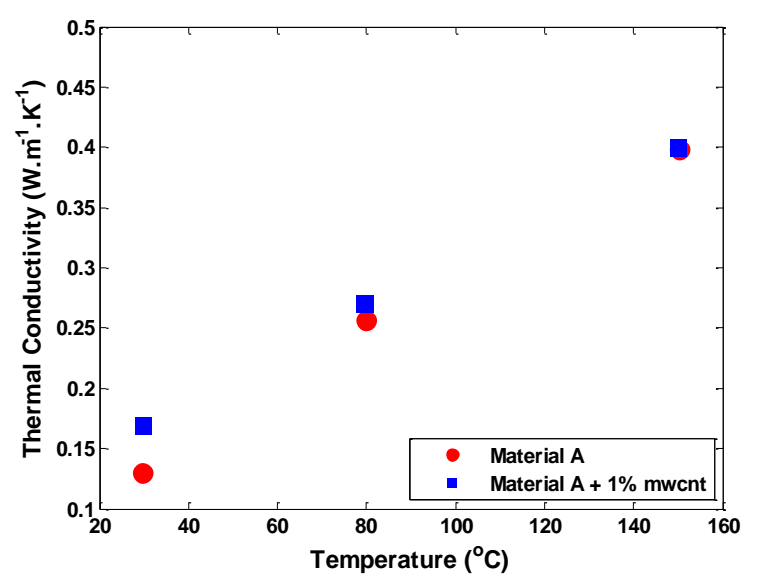

Figure 7 Thermal conductivity of Material A - Effect of carbon nanotubes.

\section{CONCLUSIONS}

In this paper we reported the investigation of a novel thermochemical storage material that combines the zeolite $13 \mathrm{x}$ and a two salts: magnesium sulphate $\left(\mathrm{MgSO}_{4}\right)$ and magnesium chloride $\left(\mathrm{MgCl}_{2}\right)$. The zeolite act as a supporting matrix for the salts which are hosted onto the pore surface area of the zeolite. Such a composite stores thermal energy in the form of dehydration/hydration heat of the salts and sorption/desorption heat of the zeolite. Solar thermal energy storage in buildings is the target application for the material. We found that a 50/50\% ratio of magnesium sulphate and magnesium chloride maximize the energy storage density $(\sim 400 \mathrm{~kJ} / \mathrm{kg})$, while other salts ratios actually reduces the storage density of pure zeolite. This suggests a possible interaction between salts in the zeolite that might cause pore blockage. As a results, water mass transfer from/to reaction is obstructed

\section{REFERENCES}

[1] Great Britain. Climate Change Act 2008, London, www.legislation.gov.uk/ukpga/2008/27/contents

[2] Energy Technology Perspective 2014 Harnessing Electricity's Potential. IEA - International Energy Agency. http://www.iea.org/Textbase/npsum/ETP2014SUM.pdf [accessed 05.01.16].
[3] Xing L., Jihong W., Mark D., Jonathan C. Overview of current development in electrical energy storage technologies and the application potential in power system operation. Applied Energy 137 (2015) 511-536.

[4] Haisheng Chen, Thang Ngoc Cong, Wei Yang, Chunqing Tan, Yongliang Li, Yulong Ding. Progress in electrical energy storage system: A critical review. Progress in Natural Science 19 (2009) 291-312

[5] de Garcia A. Cabeza L. Phase change materials and thermal energy storage for buildings. Energy and Buildings 103 (2015) 414-419.

[6] Solé A, Martorell I, Cabeza LF. State of the art on gas - solid thermochemical energy storage systems and reactors for building applications. Renewable and Sustainable Energy Reviews 2015;47:386-98.

[7] Aydin D, Casey SP, Riffat S. The latest advancements on thermochemical heat storage systems. Renewable and Sustainable Energy Reviews 2015;41:356-67.

[8] N'Tsoukpoe K.E., Restuccia G., Schmidt T., Py X. The size of sorbents in low pressure sorption or thermochemical energy storage processes. Energy 77 (2014) 983-998.

[9] L.G. Gordeeva, Y.I. Aristov, Composites 'salt inside porous matrix' for adsorption heat transformation: a current state-of-the-art and new trends, Int. J. Low-Carbon Technol. (2012) 1-15..

[10] H.A.Zondag, J.CotGores ,L.P.J. Bleijendaal, M. Bakker, R. Schuitema, W.G.J. vanHelden, V.M. vanEssen. Characterization of $\mathrm{MgSO} 4$ hydrate for thermochemical seasonal heat storage. Journal of Solar Energy Engineering (ASME) 131 (2009) 041014-1041014-7. 